\title{
Former food products safety: microbiological quality and computer vision evaluation of packaging remnants contamination
}

\author{
M Tretola, A. R Di Rosa, E Tirloni, M Ottoboni, C Giromini, F Leone, C. E. M.
} Bernardi, V Dell'Orto, V Chiofalo \& L Pinotti

To cite this article: M Tretola, A. R Di Rosa, E Tirloni, M Ottoboni, C Giromini, F Leone, C. E. M. Bernardi, V Dell'Orto, V Chiofalo \& L Pinotti (2017): Former food products safety: microbiological quality and computer vision evaluation of packaging remnants contamination, Food Additives \& Contaminants: Part A, DOI: 10.1080/19440049.2017.1325012

To link to this article: http://dx.doi.org/10.1080/19440049.2017.1325012

Accepted author version posted online: 17

May 2017.

Submit your article to this journal $\pi$

ఋ Article views: 2

View related articles

View Crossmark data $\nearrow$ 
Publisher: Taylor \& Francis \& Informa UK Limited, trading as Taylor \& Francis

Journal: Food Additives \& Contaminants: Part A

DOI: $10.1080 / 19440049.2017 .1325012$

\title{
Former food products safety: microbiological quality and computer vison evaluation of packaging remnants contamination
}

Tretola $\mathrm{M}^{1}$., Di Rosa A. $\mathrm{R}^{2}$., Tirloni $\mathrm{E}^{1}$., Ottoboni $\mathrm{M}^{1}$., Giromini $\mathrm{C}^{1}$., Leone $\mathrm{F}^{2}$., Bernardi C. E. M., Dell'Orto $\mathrm{V}^{1}$., Chiofalo $\mathrm{V}^{2}$, and Pinotti $\mathrm{L}^{1 \$}$.

${ }^{1}$ Department of Health, Animal Science and Food Safety, VESPA, Universitàdegli Studi di Milano, Milano, Italy; ${ }^{2}$ Department of Veterinary Science, Università degli Studi di Messina, Messina, Italy

${ }^{\$}$ Corresponding Author email:-luciano.pinotti@unimi.it

\begin{abstract}
The use of alternative feed ingredients in farm animal's diets can be an interesting choice from several standpoints, including safety. In this respect, the aim of this study was to investigate the safety features of selected Former Food Products (FFPs) intended for animal nutrition produced in the framework of IZS PLV 06/14 RC project by a FFP processing plant. Six FFP samples, both mash and pelleted, were analysed for the enumeration of Total Viable Count (TVC) (ISO 4833), Enterobacteriaceae (ISO 21528-1), Escherichia coli (ISO 16649-1), coagulase-positive Staphylococci (CPS) (ISO 6888), presumptive B. cereus and its spores (ISO 7932), sulphite reducing Clostridia (ISO 7937), Yeasts and Moulds (ISO 21527-1) and the presence in $25 \mathrm{~g}$ of Salmonella spp. (ISO 6579). On the same samples, the presence of undesired ingredients which can be identified as remnants of packaging materials has been evaluated by two different methods: 1stereomicroscopy according to published methods; 2 . Stereomicroscopy coupled with a computer vision system (IRIS Visual Analyzer VA400). All FFPs analysed resulted safe from microbiological point of view. Total Viable Count was limited and Salmonella was always absent. When remnants of packaging materials have been considered, the contamination level was below to $0.08 \%$ (w/w). Of note, packaging remnants were found mainly from the $1 \mathrm{~mm}$ sieve mesh fractions. Finally, the innovative computer vision system demonstrated the possibility of rapid detection of the presence of packaging remnants in FFPs when combined with a stereomicroscope. Concluding FFPs analysed in the present study can be considered safe, even though some improvements in FFP
\end{abstract}


processing, in the feeding plant, can be useful in further reducing their microbial loads and impurity.

Key words: former food products; safety evaluation; stereomicroscopy; packaging remnants; computer vision.

\section{Introduction}

Animal feed is the most important livestock production cost factor and represented in 2014 up to $85 \%$ of the farm gate value of poultry (Bouxin, 2016). In the EU-28, farmed animals consume annually around 475 million tons of feed of which $30 \%$ are compound feed. Clearly, ensuring that such high volumes of traded products conform to adequate quality standards is a major undertaking and it is fair to say that the EU has made significant progress in defining standards and promoting legislation in this area. As a consequence, the explicit and detailed formulation of the concepts of food/feed safety and food/feed quality has been consolidated, within the EU, to legislation on the traceability, control and labelling of both feed and food. These concerns are even more important when innovative feed products are considered as alternative feed ingredients. In this context, the "former food products" story represents an exhaustive example. Nowadays, in the food production chain, specific demands for quality and excess in production exist due to problems of manufacturing, packaging defects etc. The foods, which are removed from the regular food chain for economic and quality reasons, can be indicated as Former Food Products (FFPs) or ex-food (Pinotti et al., 2016, Giromini et al., 2017). According to the EU Catalogue of Feed Materials (Regulation [EC] No 68/2013) former foodstuffs are 'foodstuffs, other than catering reflux, which were manufactured for human consumption in full compliance with the EU food law but which are no longer intended for human consumption for practical or logistical reasons or due to problems of manufacturing or packaging defects or other defects and which do not present any health risks when used as feed'. Typical former foodstuffs are represented by raw materials with high energy content in the form of sugars, oils and starch such as biscuits, bread, breakfast cereals, chocolate, pasta, bakery products and snacks. The Feed Materials Catalogue therefore also specifically stipulates that 
former foodstuffs are inherently different from catering waste, whose use in animal feed is prohibited in the EU (EFFPA, n.d.). Nowadays, over 3 million tons of so-called former foodstuffs are produced in the EU, even though not all are re-converted and re-valorised as animal feed, with a consequent waste of highly nutritional material when former food products are not used as ingredient of animal feed (Featherstone, 2016). The main reason of the limited use of ex-food is their poor characterisation not only from a nutritional point of view, but also from a safety standpoint. Pre-requisites to improve the use of these innovative feed ingredients consist in a minimisation of risks and in an increased valorisation. The valorisation of FFPs entails considering several safety aspects such as microbiological quality and remnants of packaging material contamination levels.

Animal feed, due to its composition, provides a favourable environment for the growth of microorganisms. Moisture, temperature, type of feed, chemical and physical properties of raw material, $\mathrm{pH}$ values, storage conditions and much more, represent factors that can modulate bacterial growth and proliferation (Andreoletti et al., 2008). Bakery products and cooked materials that mainly represent FFPs can generally be considered microbiologically stable. However, feed contamination may occur during processing, transport or storage. Moreover, the process of removing the food packaging can be a source of contamination. For all these reasons, verification of the microbiological quality of these materials is always recommended, when they are used as animal feed.

A further aspect that has been reported in term of safety is referred to packaging material remnants. Processing methods to convert former food in to feed ingredients do not usually include preremoval of packaging materials. For this purpose, feed processors routinely remove the packaging from ex-food mechanically in the feed plant but, despite the removal of most part of the packaging, small amounts of wrapping materials can remain in the resulting feed. As a result a small amount of packaging remnants in the final product (feed) appears to be unavoidable (Marchis et al. Personal 
communications). Classical remnants which residue in former food are plastics, paper and aluminium foils.

The remnants of packaging (Regulation [EC] 1935/2004), are often characterised by complex compositions and large variety of materials. According to the General Food Law principles (Regulation [EC] No 178/2002) and the Feed Hygiene requirements (Regulation [EC] No 183/2005), traceability and safety shall be guaranteed at any stage of the food and feed chain. This scenario imposes a proper approach in defining appropriate methods for detecting possible packaging contaminants and their remnants in ex-food used in the feed chain. Recently, van Raamsdonk and co-workers (2012) validated a method (RIKILT) for detection and quantification of packaging materials in bakery products. Nevertheless, this method can be considered very laborious and the basic principle of this method is to separate every particle that is not native to the matrix by naked eye examination. In the light of this, the aim of this study was to investigate the safety features, in term of microbiological quality and packaging remnants contamination by different methods, of specific FFPs intended for animal nutrition.

\section{Materials and methods}

\section{Sample}

In this study six samples of mixed FFPs, collected in the frame of IZS PLr V 06/14 RC project, have been used. All samples were produced starting from different food materials [e.g. broken biscuits and chocolates, confectionery products (e.g. croissant, chocolate), surplus bread, rice cakes, and breakfast cereals], in an ex-food processing plant based in the north of Italy. Four samples were in meal form whereas two of them were pelleted. Samples have been received in paper bags and stored at the temperature of $4{ }^{\circ} \mathrm{C}$ until analyses. 


\section{Microbiological analyses}

Samples were received in refrigerated conditions. For microbial counts, 10 grams of each sample were homogenized in $90 \mathrm{ml}$ of diluent solution $(0.85 \% \mathrm{NaCl}$ and $0.1 \%$ peptone $)$, and then serial 10 fold dilutions were made in sterile saline.

Total Viable Count (TVC), was determined on Plate Count Agar (PCA) (Biogenetics, Ponte San Nicolò, Italy) according to NF EN ISO 4833:2003 method.

The number of Enterobacteriaceae was determined on Violet Red Bile Glucose Agar (VRBGA) (Biogenetics) according to the NF EN ISO 21528-2:2004 method. E. coli counts were determined on TBX (Oxoid, Basingstoke, UK) according to the NF EN ISO 16649-1:2001 method.

Coagulase positive Staphylococci were determined on Baird Parker Agar (BP) (Biogenetics) supplemented with Egg Yolk Tellurite emulsion (Biogenetics) following the method NF EN ISO 6888-1:1999.

Presumptive B.cereus, a spore-forming, were enumerated on PEMBA medium (Biogenetics) according to NF EN ISO 7932:2004. Spores of presumptive B. cereus were enumerated on the same medium after pasteurization of the dilutions $\left(80^{\circ} \mathrm{C}, 10 \mathrm{~min}\right.$.). Count of spores of sulphite-reducing Clostridia was performed on Tryptose Sulphite Cycloserine Agar (TSC) (Oxoid) according to the ISO 7937-2004 method, after pasteurization of the dilutions. Yeasts and Moulds were enumerated onto Sabouraud Dextrose Agar (SAB) (Scharlau, Barcelona, Spain) supplemented with Tetracycline (10 mL/1) according to NF EN ISO 21527-1:2008. Salmonella spp. detection was performed on 25 grams of each sample by the method NF EN ISO 6579:2002.

\section{Experiment 1: Detection and quantification of packaging materials by stereomicroscope.}

The presence of undesired ingredients which can be identified as remnants of packaging materials has been evaluated in meal and pelleted samples by a stereomicroscopy technique, according to 
Raamsdonk et al. (2012) and Marchis et al., (2016), with minor adaptations. Briefly, $100 \mathrm{~g}$ of each sample was weighed in a $600 \mathrm{ml}$ beaker and sieved at mesh sizes of $4 \mathrm{~mm}, 2 \mathrm{~mm}, 1 \mathrm{~mm}, 800 \mu \mathrm{m}$, $630 \mu \mathrm{m}, 400 \mu \mathrm{m}, 250 \mu \mathrm{m}$ and $125 \mu \mathrm{m}$. For pelleted samples, the wet sieving procedure was performed according to Miladinovic (2009). Specifically, $100 \mathrm{~g}$ of each sample was weighed in a $600 \mathrm{ml}$ baker. The pellet was soaked for 2 hours in approx. $500 \mathrm{ml}$ of room temperature tap water. Pellets were stirred at least once after the first hour for best results. When completely dissolved, the sample was sieved using a water flow to wash all of the particles. Sieves were placed on a rack in the oven at $104^{\circ} \mathrm{C}$ (standardized European procedure-EU 71/393), and left to dry-out over-night. Each sieve with the dried material was weighted. For all FFPs, each sieve fraction was investigated separately for remnants of presumed packaging materials with stereo-microscope (OLYMPUS SZX9) in a large plate with upright borders. All extraneous particles have been isolated and collected. The selected particles were picked up by a pair of tweezers. When necessary, a larger magnifying glass was used. The specific sieved portions of remnants of presumed packaging material were kept separated for the entire process. Each sieved portions of selected material were weighted and the amount was used to calculate the percentage $(\mathrm{w} / \mathrm{w})$ of remnants of presumed packaging materials per fraction and for the entire sample.

\section{Experiment 2: Detection of packaging materials by Computer Vision.}

All the samples have been analysed using a Computer Vision System (CVS) (IRIS Visual Analyser VA400). In a preliminary trial all samples have been analysed according to manufacture instructions (IRIS Visual Analyser Alpha Soft V14 Manual) with minor adaptations. In brief, each sample was positioned on the available surface and submitted to top and bottom controlled white lighting conditions $\left(6500^{\circ} \mathrm{K}\right)$ to avoid shadow effects. A picture of the sample surface was taken by the use of a high resolution CCD camera (16 million colours). In this trial, due to the small particles size of both feed material and packaging remnants, it was not possible to obtain highresolution pictures for an appropriate image analysis. For this reason, a further approach has been 
adopted. Specifically, the CVS (IRIS Visual Analyser VA400) technique was coupled with stereomicroscope image analysis. Briefly, 2 grams randomly composed of each FFP were weighted; pelleted samples were previously ground with mortar and pestle. In order to define an internal reference material, i.e. a FFP cleaned-sample, the cleanest FFP resulted from the experiment 1was used. For this purpose, in FFP6 all visible packaging remnants have been removed. Correspondence w/w packaging remnants levels between experiment $1(100 \mathrm{~g})$ and the sub-samples $(2 \mathrm{~g})$ used in experiment 2 was verified. Packaging materials recovered in the samples (by visual inspection) and in sub-samples used for CVS have shown a correlation of $\mathrm{r}=0,997(\mathrm{P}<0.001)$.

For each sample, about 30 pictures $(6.3 \mathrm{X})$ of sample fractions were obtained (CoolSNAP-Pro colour camera). The pictures which were obtained were uploaded on the CVS AlphaSoft software (Alpha MOS, France) and analysed. Specifically, for colour analysis the image background of the FFPs pictures was first removed, by a pre-processing method (AlphaSoft software), in order to limit the analysis to the FFP colours. Afterwards, the pictures were processed as a colour spectrum representing the proportion of each colour (\%) on the FFP surface, within a fixed scale of 4096 colours, corresponding to a unique set of 3 values in the Red Green Blue (RGB) space. To automate the visual quality control of FFPs, the visual parameters measured with CVS were processed using Statistical Quality Control (SQC) model.

\section{Statistical analysis.}

Pearson correlation between packaging remnants levels in experiment 1 samples and cleaned FFP sample obtained in experiment 2 were determined using SPSS (SPSS/PC Statistics 23 SPSS Inc., Chicago, 207 IL).

Regarding the computer vision analyses, starting from the colour spectrum (percentage of the different visible colours) obtained from samples and reference material (cleaned-FFP sample) surface, the AlphaSoft software (Alpha MOS, France) has been used to build up the SQC chart for 
statistical monitoring of sample quality (presence/absence). Using the cleaned-FFP, the training phase has been performed in order to relate the variability of the sample to the sensor data recorded by the analysis system. In this statistical approach, average value (mj) and a standard deviation $(\delta \mathrm{j})$ from the responses of each sensor "j" have been calculated. To build the SQC model, the colourcode 4095 sensor has been selected as the most discriminating variable. By multivariate analysis, the visual difference between the training sample and FFP samples has been estimated. The software expresses the difference as a distance. The resulting chart has been constructed with an acceptability area defined by the upper and lower limits (horizontal lines). To set limits of the SQC graph, the AlphaSoft software (Alpha MOS, France) uses the following acceptability index (or rejection probability):

I acceptability $=(1-$ Prejection $) \times 100$ with $0<$ Prejection $<1$

Samples mapped into acceptability area have been recognized as uncontaminated. Conversely, samples mapped outside this area have been recognized as contaminated by presumed packaging remnants.

\section{Results and discussion}

\section{Microbiological quality}

Microbiological analyses showed that all the six samples examined were of a high microbiological standard and free from pathogenic organisms (Table 1). For the evaluation of microbial counts, commonly used to evaluate the general hygienic condition of food and feedstuffs, as no official microbiological guidelines for feed samples are available, those for food for human consumption were considered (Health Protection Agency, 2009). Mean Total Viable Count (TVC), parameter commonly used to evaluate the general hygienic condition of food and feedstuff, resulted to be 4.92 $\pm 0.25 \mathrm{Log} \mathrm{CFU} / \mathrm{g}$. None of the samples exceeded the microbial loads of $6 \mathrm{Log} \mathrm{CFU} / \mathrm{g}$, generally recognized in food as the threshold limit above which spoilage could occur (Health 
Protection Agency, 2009). These results were expected as the analysed feedstuffs are characterized by low moisture content and a very high temperature reached during the production process. Mean count of Enterobacteriaceae, used as faecal contamination index for feedstuff, was $3.61 \pm 0.55 \log$ $\mathrm{CFU} / \mathrm{g}$, confirming the low level of bacterial contamination; the product FFP3 showed counts below the detection limit ( $2 \mathrm{Log}$ CFU/g)with all samples within the threshold safety limit for the animal feed sector of 10 Log CFU/g established by Regulation (EC) No 142/2011.E. coli resulted to be always under the detection limit, while Staphylococci count resulted to be extremely low ( $>2$ $\log \mathrm{CFU} / \mathrm{g}$ ), except for FFP2 in which it reached $2 \mathrm{Log} \mathrm{CFU} / \mathrm{g}$. Levels of B. cereus and its spores, potential pathogenic aerobic microorganism occurring ubiquitously in several natural habitats and food products, were on average below $3 \mathrm{Log}$ CFU/g (2.84 \pm 0.73$)$. Generally, these bacteria never exceed the level of $5 \mathrm{Log} \mathrm{CFU} / \mathrm{g}$, recognised as the starting concentration from which toxin production may occur. Not all B. cereus strains produce toxins and are able to produce gastrointestinal disease, but levels $>5 \mathrm{Log} \mathrm{CFU} / \mathrm{g}$ are considered indicators of poor processing, poor quality of raw materials, or poor temperature control. Clostridia were found countable just in 2 of the 6 samples and in very low loads (1.70 and 1.0 Log CFU/g in FFP2 and FFP3 samples, respectively); levels $<1 \mathrm{Log}$ CFU/g are considered satisfactory, and commonly $<4 \log \mathrm{CFU} / \mathrm{g}$ not of particular apprehension. Clostridia count is used as a marker of the effectiveness of thermal treatments during production process. Yeasts and moulds, which are among the most critical organisms for this type of feedstuff, were detected in all the samples, with loads around 3-4 Log $\mathrm{CFU} / \mathrm{g}$ (mean values $4.03 \pm 0.56$ and $3.30 \pm 0.41 \mathrm{Log} \mathrm{CFU} / \mathrm{g}$ respectively). Moulds can negatively affect feed quality, reducing dry matter and nutrients contents. Mouldy raw materials are not appetizing and can considerably reduce feed consumption (Liu, 2011). However, levels found should be considered not of particular concern since yeasts may cause alteration at levels around 6$7 \mathrm{Log} \mathrm{CFU} / \mathrm{g}$ and the loads of moulds do not indicate spoilage of the product. The Panel on Biological Hazards identified Salmonella spp. as the major hazard for microbial contamination of animal feed. Transmission of Salmonella from animal feed to animals consuming the feed and to 
food products derived from the animals has been shown in several studies. In all FFPs tested in the present study, Salmonella spp. was never detected, matching the requirements included in Regulation (EC) No 142/2011 for the animal feed sector.

\section{Packaging remnants analysis}

In this study, FFPs have shown a mean level of packaging materials remnants of $0.02 \%$ (w/w). Specifically, in mash FFPs samples the remnants contamination was below $0.08 \%$ (w/w), whereas in pelleted samples was $0.02 \%(\mathrm{w} / \mathrm{w})$. The possible effects of feed processing (i.e. pelleting) are unknown. FFP2 showed the highest packaging remnants level $(0.07 \%$ w/w), whereas FFP4 and FFP6 showed the lowest one $(0.005 \% \mathrm{w} / \mathrm{w})$ (Figure 1). However, despite the low quantity of packaging remnants recovered, in FFP4 an abundant amount of light spots which look like plastic fragments, were observed (Figure 3). These presumed remnants materials were too small for a systematic (manually) collection and their subsequent quantification. In this respect, it can be suggested that the methods tended to underestimate the packaging remnant contamination, even though as reported elsewhere (van Raamsdonk et al., 2012) these small particles in term of quantity are insignificant. Furthermore, the German Federal Ministry of Food, Agriculture and Consumer Protection (Bundesministerium für Ernährung, Landwirtschaft und Verbraucherschutz, BMELV) acknowledged that presence of packaging material in bakery products and confectionery, should not result in significant risks within tolerance level of $0.125 \% \mathrm{w} / \mathrm{w}$ (Kamphues, 2005). In this study, all FFPs tested showed presumed packaging remnants level below the tolerance level established by BMELV.

Of note, the distribution of packaging remnants was heterogeneous among different sieve meshes in all samples. In particular, remnants were observed mainly from the 1-mm sieve mesh fraction (Figure 2). Quantification of particles smaller than the sieve mesh size of $400 \mu \mathrm{m}$ would be too laborious and, according to Raamsdonk et al. (2012), these small particles present in the two smallest fractions were excluded from the quantification, since the share in the total weight is 
insignificant. Furthermore, the contribution of the particles larger than $2 \mathrm{~mm}$ to the total amount of material in the samples was insignificant.

Based on these results it can be concluded that FFPs are safe, even though some improvements in FFP processing, at the feeding plant, can be useful in further reducing their impurity.

\section{Computer Vision Analyses}

Computer Vision System allowed a visual assessment of sample appearance, determining the proportion of each visible colour across the surface of the samples (i.e. FFPs). Moreover, the advanced data processing software (Alpha MOS, France) offered the possibility to perform a Statistical Quality Control (SQC) among FFPs by comparison of their colour spectrum (percentage of the different visible colours). Its approach however should be considered qualitative (presence/absence).

Preliminary colorimetric analysis of FFPs pictures showed that a specific colour code, i.e. 4095, was always present in samples' pictures where presumed packaging remnants was present. The same colour code was absent in samples pictures without packaging remnants. The occurrence of 4095 colour code in pictures where packaging remnants have been observed, could be due to the particular reflecting properties of some packaging materials, such as aluminium foil and plastics. Although the definition of "plastic" refers to several types of packaging materials (van Raamsdonk et al., 2011), such as polyethylene (PE) polypropylene (PP), polyvinyl chloride Rigid (PVC), polystyrene (PS), polyethylene terephthalate and its copolymers (PET) (Marchis et al. Personal communication), this result is in agreement with Ramdsdonk et al.(2012), who reported that fibres of papers, fragments of plastic, aluminium foil and chips of plastic clips are most recovered types of material detectable in FFPs. Therefore, 4095 colour code could be associated with the presence of packaging remnants in FFP samples.

In light of these findings, a further step in the study was the SQC analysis. Through the SQC model, 
the presence of the colour code 4095 in the six FFP samples, in comparison with a cleaned FFP, was performed. As reported in the figure 4, in samples FFP1, FFP2, FFP3, FFP4, FFP5, presence of packaging remnants have been recorded, even though with some differences between samples. In facts, with the exception of FFP4 and FFP6, all the other samples (FFP1, FFP2, FFP3, and FFP5) have shown a presence, at very low level, of packaging material. The four samples have been plotted outside this grey band (area of tolerance), indicating that they were contaminated by packaging remnants, as shown in figure 5. A completely different pattern in the SQC analysis has been obtained for FFP4, which was plotted as very distant from the cleaned FFP sample in the CVS analysis. The reason of that is unknown, even though the nature of these presumed packaging materials, especially in term of colour attribute, could be implicated. This discrepancy between methods can be attributed to the presence of abundant reflecting light spots in the sample (Figure 3), presumably originated by packaging materials, that were detected by the CVS, but too small for a systematic measurement by the classical method. A further exception, in comparison with the conventional method was the sample FFP6. This latter has shown a SQC pattern very close to the cleaned sample FFP, i.e within the area of tolerance, probably due to the fact that it was the lowest contaminated sample.

Combining these results it can be concluded that although detailed studies will be necessary to clarify the nature of this material, CVS and the SQC analysis seems to be informative in distinguishing between contaminated and uncontaminated samples. This method even though qualitative for the moment, can be considered effective in defining further analysis or investigations in former food products.

\section{Conclusions}

The present study investigated the two main safety issues linked to the use of ex-food in animal nutrition. All FFPs analysed were found to be safe from a microbiological point of view and among the samples collected, Salmonella spp. was always absent. All the loads of the other microbiological 
contaminants were moderate or not detectable, always within tolerance levels established by Health Protection Agency and European Regulation No 142/2011. These results indicate a high quality of the these former foodstuffs, suggesting the low risk level of the production process. When remnants of packaging materials were considered, the contamination level measured in the present study was below $0.08 \%(\mathrm{w} / \mathrm{w})$. Of note, presumed packaging remnants showed heterogeneous distribution among different sieve meshes fractions in all samples. In particular, the packaging remnants were observed mainly from the $1 \mathrm{~mm}$ sieve mesh fraction. These results indicated that all samples were significantky below tolerance level of $0.125 \%(\mathrm{w} / \mathrm{w})$ proposed by a EU member state authority (German, BMELV). Moreover, contamination levels of up to $0.15 \%$ w/w are considered not only unavoidable in bakery products, but also not significant in term of safety risks. In term of methods of analysis, even though a validated (RIKILT) method for detection and quantification of packaging materials in bakery products exist, innovative complementary methods based on a Computer Vision System, has been proposed. Results suggest a possible application of this method to perform a rapid detection of the presence/absence of presumed packaging remnants in ex-food that can prelude or integrate the validated method. This method has shown a big potential in detecting efficiently the presence/absence of presumed packaging remnants also in low contaminated ex-food.

Based on these results, it can be concluded that FFPs can be considered safe feed ingredients, even though some improvements in FFP processing, at the feeding plant, and specific implementations in innovative methods of analysis, can be useful in further reducing their microbial loads and impurity.

\section{Acknowledgments}

This study was supported by IZS PLV 06/14 RC project, funded by the Italian Ministry of Health. 


\section{References}

Andreoletti O, Budka H, Buncic S, Colin P, Collins JD, DeKoeijer A, Griffin J, Havelaar A, Hope J, Klein G. et al. 2008. Microbiological risk assessment in feedingstuffs for food-producing animals Scientific Opinion of the Panel on Biological Hazards. EFSA J, 720, 1-84.

Bouxin A. 2016. Use of food co-products in the feed sector: opportunities and challenges. Available from: http://www.elc-eu.org/uploads/news_documents/FEFAC_-_Food_coproducts_in_feed.pdf.

EFFPA (European Former Foodstuff Processors Association): What are former foodstuffs?

[Internet].[cited 2017 Jan 15].Available from: http://www.effpa.eu/what-are-formerfoodstuffs/.

European Commission, 2002. Regulation (EC) No 178/2002 of the European Parliament and of the Council of 28 January 2002 laying down the general principles and requirements of food law, establishing the European Food Safety Authority and laying down procedures in matters of food safety. Official Journal L 031 , 01/02/2002 P. 0001 - 0024.

European Commission, 2004. Regulation (EC) No 1935/2004 of the European Parliament and of the Council of 27 October 2004 on materials and articles intended to come into contact with food and repealing Directives 80/590/EEC and 89/109/EEC

European Commission, 2005. Regulation (EC) No 183/2005 of the European Parliament and of the Council of 12 January 2005 laying down requirements for feed hygiene (Text with EEA relevance). Available from: http://data.europa.eu/eli/reg/2005/183/oj.

European Commission, 2011. Regulation (EC) No 142/2011 of 25 February 2011 implementing Regulation (EC) No 1069/2009 of the European Parliament and of the Council laying down health rules as regards animal by-products and derived products not intended for human consumption and implementing Council Directive 97/78/EC as regards certain samples and items exempt from veterinary checks at the border under that Directive Text with EEA relevance. Annex XIII, chapter 2. Availablefrom: http://eur-lex.europa.eu/legalcontent/EN/TXT/HTML/?uri=CELEX:32011R0142\&qid=1482831391578\&from=en.

European Commission, 2013. Regulation (EU) No 68/2013 of 16 January 2013 on the catalogue of feed materials, Official Journal of the European Union, L 29 (1) (2013). Available from: http://data.europa.eu/eli/reg/2013/68/oj.

Featherstone P. 2016. Challenges in Global Raw Material Supply: New raw materials. Available from: http://assets.nevedi.nl/p/229376/8_\%20Presentatie\%20P_\%20Featherstone.pdf. 
Giromini C, Ottoboni M, Tretola M, Marchis D, Gottardo D, Caprarulo V, Baldi A, Pinotti L. 2017. Nutritional evaluation of former food products (ex-food) intended for pig nutrition. Food Additives \& Contaminants: Part A, doi: 10.1080/19440049.2017.1306884.

Health protection Agency 2009. Guidelines for Assessing theMicrobiological Safety of Ready-toEat Foods. London:Health Protection Agency, November 2009. Available from: https://www.gov.uk/government/uploads/system/uploads/attachment_data/file/363146/Guid elines_for_assessing_the_microbiological_safety_of_ready-to-eat_foods_on_the_market.pdf

Kamphues J. 2005. Expert report on Foreign Materials in Feedstuffs.InstitutfürTierernährung, Hannover, Germany. 26pp.

Liu YL, Meng GQ, Wang HR, Zhu HL, Hou YQ, Wang WJ, Ding BY. 2011. Effect of three mycotoxin adsorbents on growth performance, nutrient retention and meat quality in broilers fed on mould-contaminated feed. British poultry science, 52(2), 255-263.

Marchis D, Giovannini T, Amato G, Ceppa L, Pinotti L, Gili M. 2016. Development and validation of a method for detection and quantification of packaging residues in feed from former food. Page 59 in book of abstract OF "FEED 2016", $5^{\text {th }}$ International feed conference: present and future challenges, Geel, 19-20 October 2016, Belgium.

Miladinovic D. 2009. Wet Sieving procedure on a "Retsch AS 200 Control" for feed manufactured pellets or feed compound. Fôrtek - Norwegian University of Life Science (UMB).

Pinotti L, Giromini C, Ottoboni M, Tretola M, Cheli F, Baldi A. 2016. Ex-food4feed: quality \& safety. In: Celebrating food : proceedings / J. Lević ; [a cura di] J. Lević, R. Čolović, Đ. Vukmirović. - Prima edizione. - Novi Sad : University of Novi Sad , Institute of Food Technology, 2016. - ISBN9788679940513. - pp. 101-105.

Raamsdonk LWD. van, Pinckaers VGZ, VliegeJJM,Egmond HJ van.2012. Examination of packaging materials in bakery products: a validated method for detection and quantification. RIKILT Report 2012.007

Raamsdonk LWD yan, Rijk R, Schouten GPJ, Mennes W, Meijer GAL, Poel AFB van der, de Jong J. 2011. A risk evaluation of traces of packaging materials in former food products intended as feed materials. RIKILT Report 2011.002 


\section{Legends for figures}

Figure 1. Packaging remnants contamination $(\% \mathrm{w} / \mathrm{w})$ in all FFPs samples. The percentage levels 2 of contamination in FFPs samples were determined weighing packaging remnants by the sieving 3 procedure and manual selection. Asterisk (*) indicates Pelleted Samples. 4

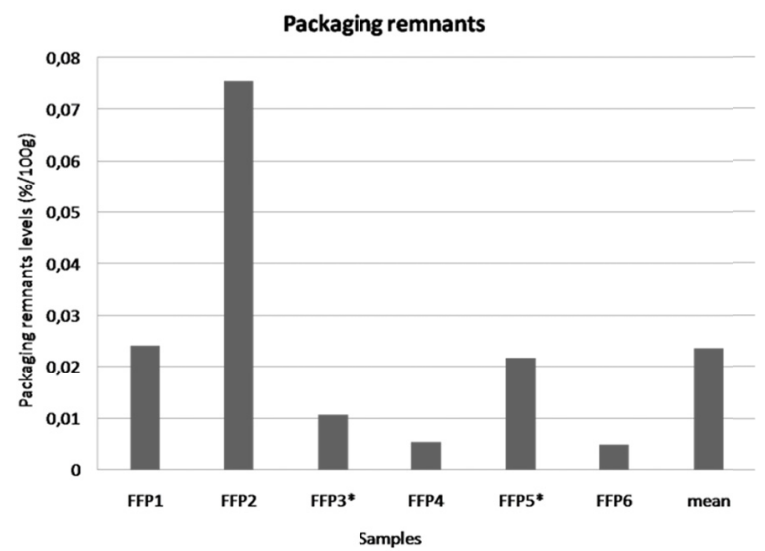

Figure 2. Packaging remnants level mean distribution. Asterisk (*) indicates Pelleted Samples 5

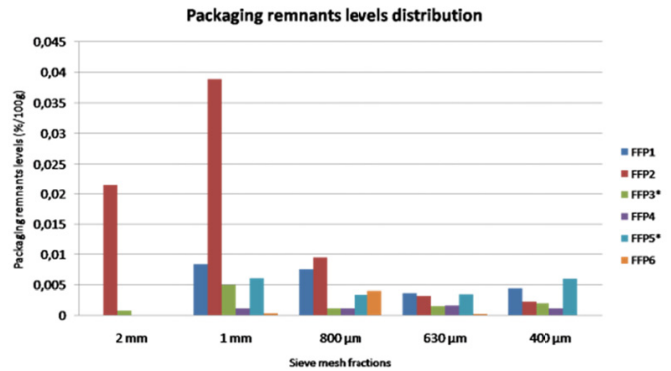


Figure 3. Light spots detected in FFP4 by the use of stereomicroscope OLYMPUS SZX9 (6.3X). 6
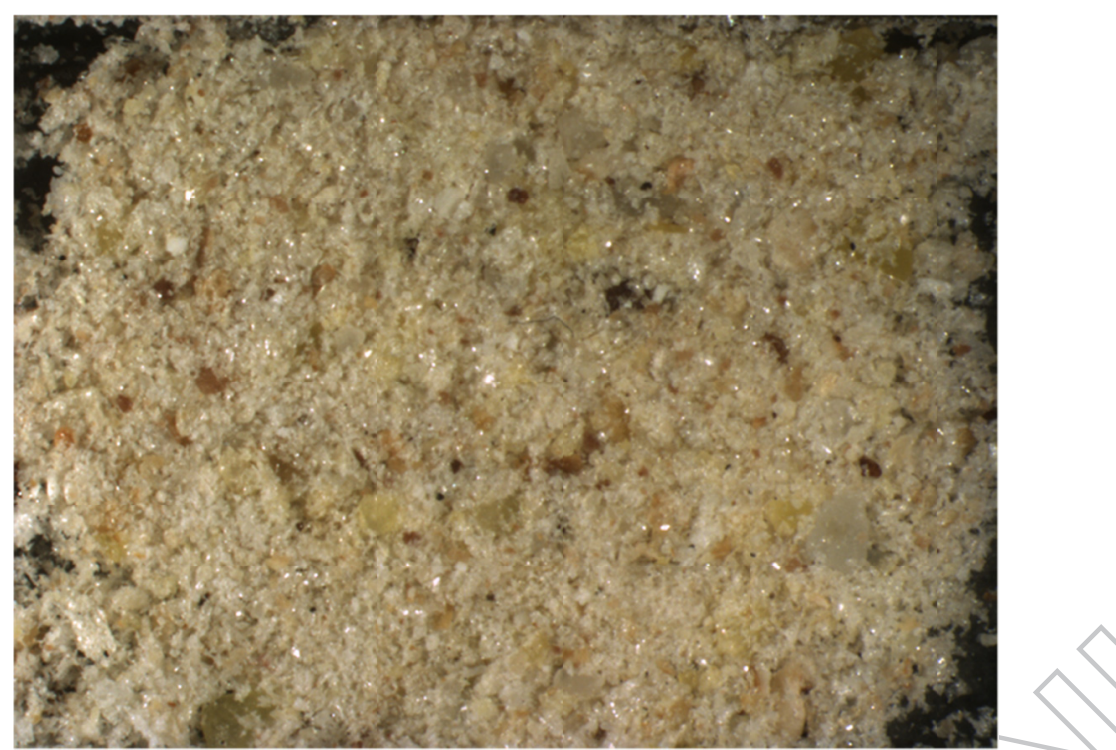

Figure 4. SQC chart. Each symbol represents a picture of the corresponding sample, based on its 7 colour. The grey area indicates the range distance obtained by the use of cleaned FFP sample in the 8 training phase. Symbols plotted outside the grey band indicate sample's pictures characterized by 9 the presence of packaging remnants, specifically significant percentage of the color code 4095.10

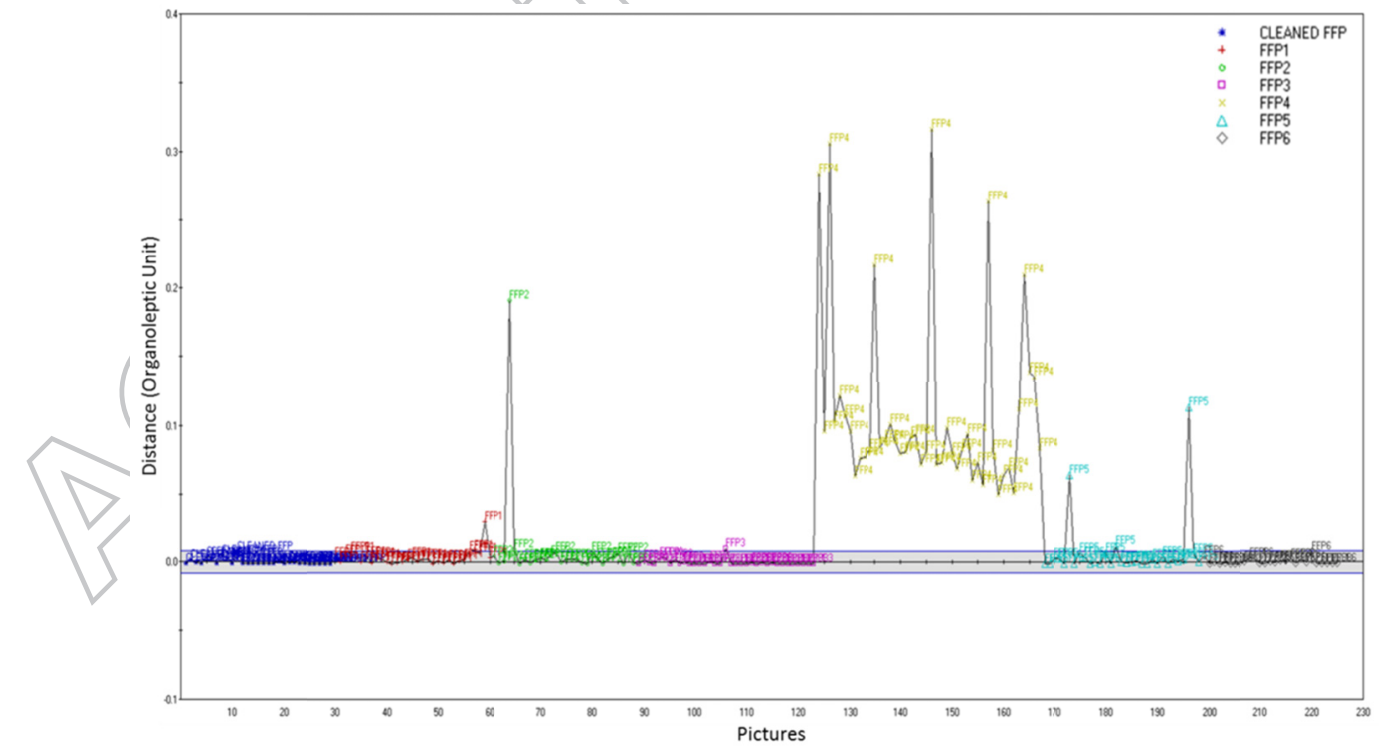


Figure 5. Presumed packaging remnants detected by visual analyser in selected samples' pictures 11 (OLYMPUS SZX9), namely: FFP1 (A) FFP2 (B) and FFP 5 (C, D) samples.
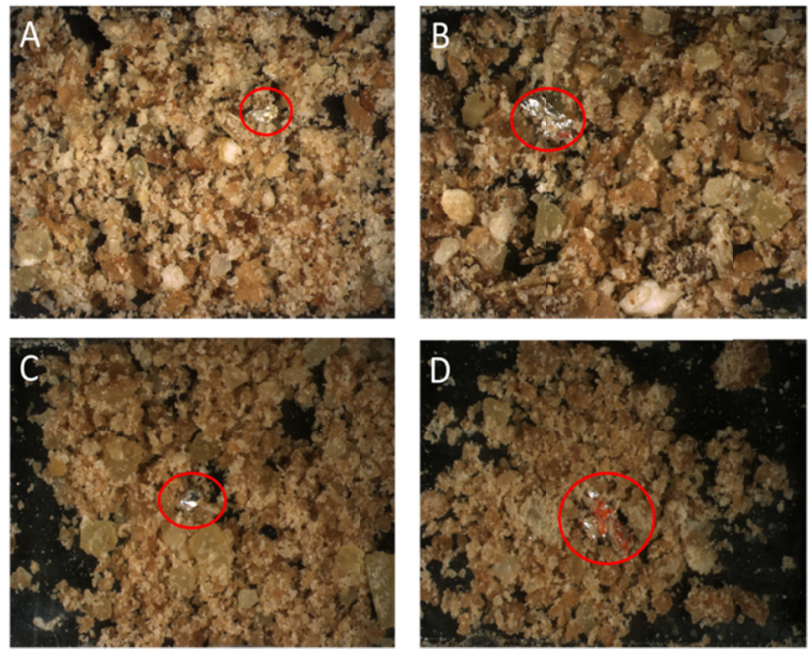

Table 1: Microbiological quality of FFPs

\begin{tabular}{|c|c|c|c|c|c|c|c|c|c|c|}
\hline & \multicolumn{10}{|c|}{ Contaminant / Threshold limit (Log CFU/g) } \\
\hline $\begin{array}{c}\text { Sam } \\
\text { ple }\end{array}$ & $\underset{\mathbf{6}^{\dagger}}{\text { TVC / }}$ & $\begin{array}{c}\text { Enterobacteri } \\
\text { aceae } / 10\end{array}$ & $\begin{array}{l}E . \\
c o \\
i i \\
\\
2^{+}\end{array}$ & $\begin{array}{l}\text { Coagulas } \\
\text { e positive } \\
\text { Staphyloc } \\
\text { occi / } 4^{\dagger}\end{array}$ & $\begin{array}{c}\text { Bacillusce } \\
\text { reus / } 5^{\dagger}\end{array}$ & $\begin{array}{c}\text { B. } \\
\text { cereussp } \\
\text { ores } / 5^{\dagger}\end{array}$ & $\begin{array}{l}\text { Clostri } \\
\text { dia } / 4^{\dagger}\end{array}$ & $\begin{array}{c}\text { Yea } \\
\text { sts / } \\
7^{\ddagger}\end{array}$ & $\begin{array}{c}\text { Moul } \\
\text { ds / } \\
7^{\ddagger}\end{array}$ & $\begin{array}{c}\text { Salmon } \\
\text { ella } \\
\text { spp. / } \\
\text { absent }\end{array}$ \\
\hline FFP1 & 4,98 & & 2 & $<2$ & 3,20 & $<2$ & $<1$ & 4,38 & 3,40 & absent \\
\hline FFP2 & 5,11 & & $\begin{array}{l}< \\
2 \\
\end{array}$ & 2 & 2,00 & $<2$ & 1,70 & 4,12 & 3,26 & absent \\
\hline FFP3 & 4,90 & $<2$ & $\begin{array}{l}< \\
2\end{array}$ & $<2$ & 2,00 & 2 & 1 & 3,00 & 3,88 & absent \\
\hline FFP4 & 4,81 & 4,20 & $\begin{array}{l}< \\
2\end{array}$ & $<2$ & 3,86 & 3,70 & $<1$ & 4,21 & 3,30 & absent \\
\hline FFP5 & 4,51 & 3,81 & $\begin{array}{l}< \\
2\end{array}$ & $<2$ & 3,08 & 2 & $<1$ & 4,60 & 3,40 & absent \\
\hline FFP6 & 5,20 & 2,70 & $\begin{array}{l}< \\
2\end{array}$ & $<2$ & 2,90 & $<2$ & $<1$ & 3,88 & 2,60 & absent \\
\hline
\end{tabular}

$\dagger$ Health Protection Agency, 2009

$\$$ Regulation (EC) No 142/2011. 


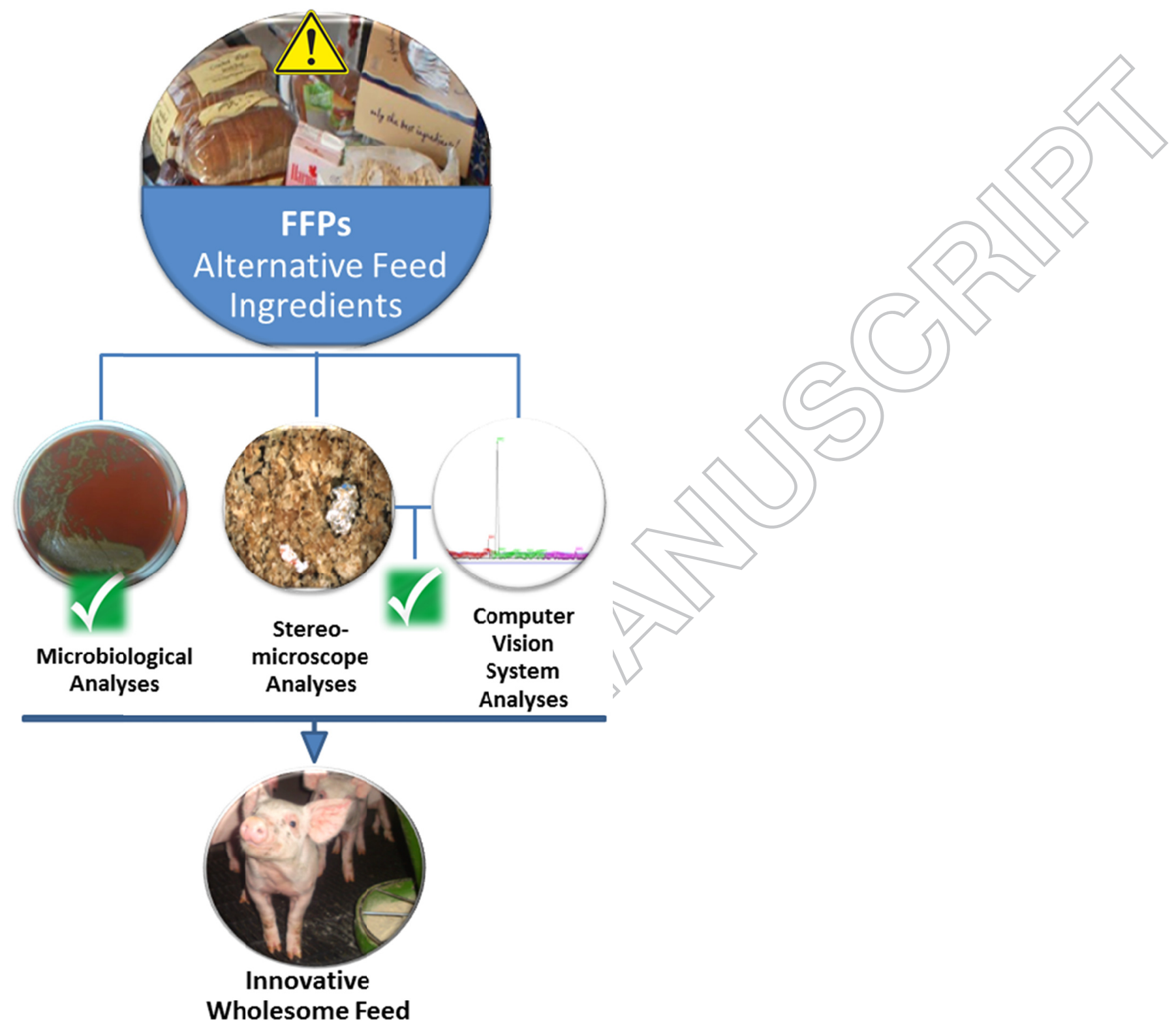

